\title{
Politique
}

Politique

\section{Le Canada et l'OTAN après 40 ans 1949-1989 sous la direction de Paul Létourneau, Centre québécois de relations internationales, Université Laval, Québec, 1992, 216 p.}

\section{Yvon Desjardins}

Numéro 22, automne 1992

URI : https://id.erudit.org/iderudit/040742ar

DOI : https://doi.org/10.7202/040742ar

Aller au sommaire du numéro

Éditeur(s)

Société québécoise de science politique

ISSN

0711-608X (imprimé)

1918-6584 (numérique)

Découvrir la revue

Citer ce compte rendu

Desjardins, Y. (1992). Compte rendu de [Le Canada et l'OTAN après 40 ans 1949-1989 sous la direction de Paul Létourneau, Centre québécois de relations internationales, Université Laval, Ouébec, 1992, 216 p.] Politique, (22), 168-170. https://doi.org/10.7202/040742ar d'utilisation que vous pouvez consulter en ligne.

https://apropos.erudit.org/fr/usagers/politique-dutilisation/ 


\section{Le Canada et l'OTAN après 40 ans 1949-1989}

Sous la direction de Paul Létourneau, Centre québécois de relations internationales, université Laval, Québec, 1992, 216 pages.

Le Traité de l'Atlantique Nord a été signé à Washington le 4 avril 1949. Douze pays, dont le Canada, acceptaient de mettre leurs forces en commun pour se prémunir contre la menace d'une attaque de l'Union soviétique. En axant ainsi leur stratégie sur les principes de la sécurité collective et de l'équilibre militaire, les états membres de cette nouvelle alliance espéraient assurer une paix durable à l'Occident. Quarante ans plus tard, malgré les nombreuses périodes de tensions et d'incertitudes auxquelles I'OTAN a dû faire face, ils ont gagné leur pari. Le Canada, bien qu'étant devenu une puissance militaire relativement faible, a néanmoins contribué aux succès de l'Alliance. Pour faire le point et du même coup souligner ces quatre décennies de paix, le professeur Paul Létourneau, du département d'histoire de l'université de Montréal, a entrepris la réalisation de ce document qui explique bien la place qu'occupe le Canada au sein de l'OTAN.

L'ouvrage collectif, d'ailleurs un des rares en français à aborder un tel sujet, regroupe les textes de sept universitaires canadiens et étrangers, intéressés par la question de l'OTAN. II a été rédigé au cours de l'année académique 1989-1990, à un moment où l'Alliance atlantique se préparait justement à amorcer une réflexion importante sur son avenir. Le recueil se veut donc à prime abord une rétrospective des événements qui ont marqué la participation canadienne à l'OTAN.

En guise d'introduction, on nous suggère le texte de Norbert Wiggershaus, historien à l'Office de recherche en histoire militaire de Freiburg, en Allemagne. L'auteur décrit d'une manière assez claire la façon dont les dirigeants des pays de l'Ouest percevaient la menace émanant de l'Union soviétique, et cela entre le début de la guerre froide et la mise sur pied de l'OTAN. Ce chapitre nous permet ainsi de bien saisir le climat tendu qui prévalait à l'époque et de comprendre les raisons véritables, tant politiques, économiques que militaires, qui ont justifié la ratification du Traité de I'Atlantique Nord.

En ayant bien à l'esprit la perception occidentale, le lecteur peut approfondir ses connaissances, dans une perspective canadienne cette fois, en abordant le deuxième chapitre consacré aux motifs qui auraient incité le Canada à se joindre à l'OTAN. Le 
professeur Létourneau, qui signe ce texte, nous propose sept facteurs dont certains sont toujours d'actualité. II cite par exemple le désir du Canada d'exercer une certaine influence sur la scène européenne et ses efforts pour diluer la trop grande influence des États-Unis au pays. Ces exemples ont justement été abordés par de nombreux spécialistes lors de l'annonce, en avril 1992, du retrait complet des Forces canadiennes de l'Allemagne. Bien qu'il ne nous apprenne rien de vraiment nouveau, le professeur Létourneau résume très bien la position du Canada dans ces années d'après-guerre.

Dans le troisième chapitre, on aborde plus en profondeur la réalité canadienne. L'auteur, le professeur Philip Windsor du London School of Economics, décrit et explique la position du Canada au cœur des grandes puissances occidentales, tout en soulignant l'importance et l'influence qu'il a eues au sein de I'OTAN. II suggère, comme beaucoup d'analystes I'ont également fait lors du débat qui a entouré l'énoncé sur la Politique de défense de 1991, que le Canada se doit de maintenir des liens étroits avec l'Europe aux niveaux politique, économique, technologique et militaire, s'il veut conserver l'influence qu'il a acquise sur la scène internationale et par le fait même une indépendance relative par rapport aux États-Unis.

Joel Sokolsky, professeur au Royal Military College de Kingston en Ontario, analyse dans le quatrième chapitre l'avenir du Canada au sein de l'Alliance atlantique face à l'engagement nordaméricain de défense collective avec les États-Unis, régie par le NORAD. L'auteur en profite pour faire ressortir la dualité qui s'est retrouvée dans la plupart des politiques canadiennes de défense depuis la fin de la Seconde Guerre mondiale. Il est également un des rares analystes à avoir prédit, deux ans avant l'annonce officielle, le retrait des Forces canadiennes de l'Allemagne, ce qui donne une certaine crédibilité à ses propos d'ailleurs fort intéressants.

Au chapitre cinq, Luc Duhamel, directeur du Programme d'Études russes et soviétiques à l'université de Montréal, aborde la politique extérieure de l'ex-Union soviétique, de la fin de la Deuxième Guerre mondiale jusqu'à 1989. II analyse brièvement les nombreux rapports qui existaient entre les pays de l'Ouest et I'URSS, de même que la perception que celle-ci en avait. Ainsi le Canada, qui ne constituait pas en soi une menace à la sécurité soviétique, a néanmoins dû accepter des rapports «marqués par l'hostilité et la confrontation" avec son voisin du nord. 
Le texte suivant, sous les plumes de Michel Fortmann, Albert Legault et Stéphane Roussel, des universités de Montréal, Laval et Montréal respectivement, aborde un thème moins bien connu du grand public : l'importance pour un pays comme le Canada d'appartenir à une organisation comme I'OTAN pour avoir accès aux tribunes importantes de l'arms control, comme par exemple la Conférence sur le désarmement en Europe. Les auteurs soulignent que même si le Canada s'est "contenté de réagir aux événements en se retranchant derrière les positions de I'OTAN", il devrait continuer à participer à ces conférences puisqu'elles lui ont permis de "disposer d'un contrepoids à l'influence américaine» sur les questions de sécurité en Europe.

En guise de conclusion, Paul Buteux, professeur au département d'études politiques à l'université du Manitoba, analyse les nombreux changements qui se sont produits en Europe et aborde la place que devrait tenir le Canada dans "l'avenir de la politique de sécurité occidentale». L'auteur anticipe également le retrait des Forces canadiennes de l'Allemagne, qu'il juge "regrettable» étant donné que la politique a "fait ses preuves dans le passé».

Le contexte international a donc beaucoup changé depuis la rédaction des textes : la guerre froide a pris fin et l'Union soviétique n'existe plus. Mais qui aurait pu en prévoir la dissolution à si court terme? Bien que nous ne puissions cependant pas attribuer ces événements aux stratégies politiques et militaires de I'OTAN, on peut reconnaître néanmoins la contribution et le rôle de l'Alliance dans le maintien de l'équilibre stratégique et de la paix en Occident. II est toutefois dommage que le recueil de textes paraisse en 1992, à un moment où l'Alliance atlantique amorce des changements qui risquent d'être très importants. Les anticipations de quelques auteurs ne correspondent pas toujours à la façon dont les événements se sont effectivement déroulés. Peut-être aurait-il été préférable de publier ce recueil en 1990, ou encore de demander aux auteurs de revoir leurs textes avant la mise sous presse. II n'en demeure pas moins que les documents présentés sont très intéressants et constituent certainement un outil pour mieux comprendre l'apport du Canada à I'OTAN. Par ailleurs, bien que le thème de la défense ne soit pas un des plus recherchés par les analystes politiques du Québec, on peut se réjouir de la parution d'un tel livre en français.

Yvon Desjardins ÉNAP - Hull 